\title{
Analysis and Optimization of Cushion Seat Supporting Members
}

\author{
Mahesh Morge $^{1}$, Sunil Mangshetty ${ }^{2}$ \\ ${ }^{I}$ Post graduate student, Department of Mechanical Engineering, PDA College of Engineering, Gulbarga, \\ Karnataka, India. \\ ${ }^{2}$ Assistant Lecturer, Department of Mechanical Engineering, PDA College of Engineering, Gulbarga,
} Karnataka, India

\begin{abstract}
Seat structures play a major role in the car passive safety. Due to their adjustment function mechanisms are generally involved in the seat failure mode. With the current evolution of automotive techniques, one of major automotive industry priorities is to decrease the product mass, design quicker and more efficient vehicles, emphasizing on travelling greater distances in short interval of time. For this comfort with safety of passengers is very important, thus the design of the seating system is very important. At the same time, seat rails have to fulfill high quality criteria, there are very strict requirements regarding strength and crash worthiness as the seat rail is regarded as a safety component it transfers forces from the driver I passenger to the car floor structure in case of a crash and they have to provide individual length adjustments possible. Amongst many parts, the seat tracks (upper and lower tracks) carry most of the load on seat structure considering human load. The aim of this project is to optimize an automotive seat track by reducing track thickness and its cost subjecting to static analysis. The adopted design has thickness of seat track as $1.5 \mathrm{~mm}$; scope of the present work involves Finite Element Modeling of Seat track assembly using HYPERMESH R 10. Pre-processing steps such as updating of element type, material properties, application of loads and Boundary condition is performed using HYPERMESH. The element type considered for the analysis is SHELL. Processing is carried using ANSYS. The results in the form of stress and displacement are extracted using HYPER VIEW.
\end{abstract}

Keywords: Seating System, Seat Track, Factor of Safety, Yield strength, Static Analysis, Von Mises Stress.

\section{Seat track}

\section{Introduction}

Tracks or rails are the mechanisms which enable to translate the seat; they are key contributors in occupant safety as link between seat and car. It provides the comfort to various size occupants by adjustment facility and also it helps to transfer the stresses to the base of the car in case of crash. It is a part of seat located at the bottom of the seat which connects to base of the car.

The main objective of a good automotive seating system is not only to provide comfort but also to provide style and more importantly the safety feature. Akbar Basha.S, et al [1] studied the Analysis and optimization of automobile seat track by reducing the thickness of the seat track. Pavan Gupta et al [2] studied that Anti-submarine Performance of an Automotive Seating System - A DOE study. But the system yet is sufficiently light weight to facilitate vehicle fuel economy and to minimize collision stresses. D. M. Severy et al were [3] developed Collision Performance LM Safety Car. Seating system design and materials must be affordable and durable to give acceptable service life. F W Babbs et al [4] studied that the packaging of car Occupants - A British Approach to seat designs.

The purpose of this project is to reduce the thickness, weight and cost of seat track.

In this present case, work is carried out by reducing the thickness of the seat track to $1.15 \mathrm{~mm}$ from $1.5 \mathrm{~mm}$ and by reducing its weight to 1.114 from 1.381. Material used in this case is different from the previous one.

\section{A. Factor Of Safety:}

Factor of safety (FOS), also known as (and used interchangeably with) safety factor (SF), is a term describing the structural capacity of a system beyond the expected loads or actual loads. Essentially, how much stronger the system is than it usually needs to be for an intended load. Safety factors are often calculated using detailed analysis because comprehensive testing is impractical on many projects, such as bridges and buildings, but the structure's ability to carry load must be determined to a reasonable accuracy.

Many systems are purposefully built much stronger than needed for normal usage to allow for emergency situations, unexpected loads, misuse, or degradation.

Factor of safety $=$ Yield strength/Von mises strength 


\section{B. Static Analysis:}

A static analysis calculates the effects of steady loading conditions on a structure, while ignoring inertia and damping effects, such as those caused by time-varying loads. A static analysis can, however, include steady inertia loads (such as gravity and rotational velocity), and time-varying loads that can be approximated as static equivalent loads (such as the static equivalent wind and seismic loads commonly defined in many building codes).Static analysis is used to determine the displacements, stresses, strains, and forces in structures or components caused by loads that do not induce significant inertia and damping effects.

\section{The Finite Element Method}

\section{Methodology And Material}

Finite element method is a numerical analysis technique for obtaining approximate solutions to a wide variety of engineering problems. Although originally developed and applied to the broad field of continuum mechanics. Because of its diversity and flexibility as analysis tool, it is receiving much attention in engineering schools and industry. In more and more engineering situation today, it is necessary to obtain numerical solutions to problem rather than exact closed from solutions. The resourcefulness of the analyst usually comes to the rescue and provides several alternatives to overcome this dilemma. One possibility is to make simplifying assumption to ignore the difficulties and reduce the problem to one that can be handled sometimes this procedure works but more often than not it leads to series inaccurate or wrong answers. Now that computers are widely available, a more viable alternative is to retain the complexities of the problem and to find an approximate numerical solution. A finite element model of a problem gives a piecewise approximation to the governing equations". The basic premise of the finite element method is that a solution region can be analytically modeled or approximated by replacing it with an assemblage of discrete elements since these can be put together in a variety of ways, they can be put together in a variety of ways, and they can be used to represent exceedingly complex shape. Two features of the finite element method are to be noted

a) The piecewise approximation of the physical field on finite elements provides Good precision even with simple approximating functions. Simply increasing the number of elements can achieve increasing precision.

b) The locality of the approximation leads to sparse equation systems for a discredited problem. This helps to ease the solution of problems having very large numbers of nodal unknowns. it is not uncommon today to solve Systems. Containing a million primary unknowns.

\section{Solution Procedure Using FEM Software}

All finite element packages require the user to go through these steps in one form to another

$>$ Specifying Geometry- First the geometry of the structure to be analyzed is defined this can be done either by entering the geometric information in the finite element package through the keyboard or mouse or by importing the model from a solid modeler like Pro-ENGINEER.

$>$ Specify Element Type and Material Properties- Next, the material properties are defined. In an elastic analysis of an isotropic solid these consist of the Young's modulus and Poisson's ratio of the material.

$>$ Mesh the Object-Then the structure is meshed into small elements. This involves defining the types of elements into which the structure will be broken, as well as Specifying how the structure will be subdivided into elements.

$>$ Apply Boundary conditions and External Loads- Next, the boundary conditions e.g. .location of supports and the external loads are specified.

$>$ Generate a solution- Then the solution is generated based on the previously input parameters.

> Post processing- Based on the initial conditions and applied loads, data is returned after a solution is processed. This data can be viewed in a variety of graphs and displays.

> Refine the Mesh- Finite element methods are approximate methods and, in General, the accuracy of the approximation increases with the number of elements Used. The number of elements needed for an accurate model depends on the Problem and the specific results to be extracted from it. Thus, in order to judge the number of elements in the object and see if or how the results change.

$>$ Interpreting Results- This step is perhaps the most critical step in the entire Knowledge of mechanics to interpret and understand the output of the model. This is critical for applying correct results to solve real engineering problems and in identifying when modeling mistakes have been made.

The key material properties that are pertinent to strength, cost and structural performance are

- Density

- Yield strength

- Young's modulus 
- Poisson's ratio

- Ultimate strength

Mechanical properties of the material are required for finite element models. There is little information on the material properties of seat rail, recliner and few components in the literature. In this project ASTM A 311/A $311 \mathrm{M}$ is used for seat rail. Table 1 describes few material properties used for analysis.

\begin{tabular}{|l|l|}
\hline Properties of Carbon Steel material & \multicolumn{2}{|l|}{} \\
\hline Young's modulus & $210 \mathrm{~N} / \mathrm{mm} 2$ \\
\hline Density & $7850 \mathrm{~kg} / \mathrm{mm} 3$ \\
\hline Poisson's ratio & 0.3 \\
\hline Yield strength & $250 \mathrm{Mpa}$ \\
\hline Ultimate strength & $450 \mathrm{Mpa}$ \\
\hline
\end{tabular}

Table 1

\section{Result and Discussion}

In this present work seat track is analyzed by following iterations. In iteration 1 seat track is analyzed by putting a load of $70 \mathrm{~kg}$ on seat track of $1.5 \mathrm{~mm}$ thickness and result obtained is not within the limit as the FOS is not in the range of 3-3.5, so the work is further proceeded for iteration 2 by changing the seat track thickness to $1.25 \mathrm{~mm}$ and maintaining the same load and the result obtained is not in the limit, hence the work is further proceeded for iteration 3 by changing the seat track thickness to $1.15 \mathrm{~mm}$ and maintaining the same load and the result obtained is within the limit. Hence by knowing that a seat track of $1.15 \mathrm{~mm}$ thickness bearing $70 \mathrm{~kg}$ of load has a FOS within the limit further iterations are carried out by increasing the load on seat track of same thickness to analyze whether it withstands more than $70 \mathrm{~kg}$ of load or not. Iteration 4 is carried out by increasing the load to $90 \mathrm{~kg}$ and the result obtained is not within the required limit, hence the work is further proceeded for iteration 5 by reducing the load to $80 \mathrm{~kg}$ and the result obtained is not within the limit. From the below table result is concluded.

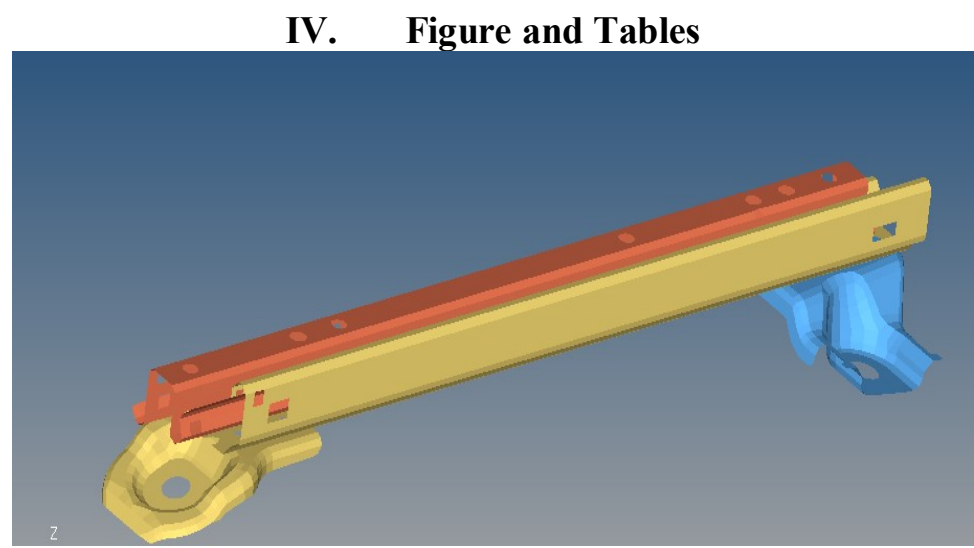

Fig: 1 CAD model of seat track.

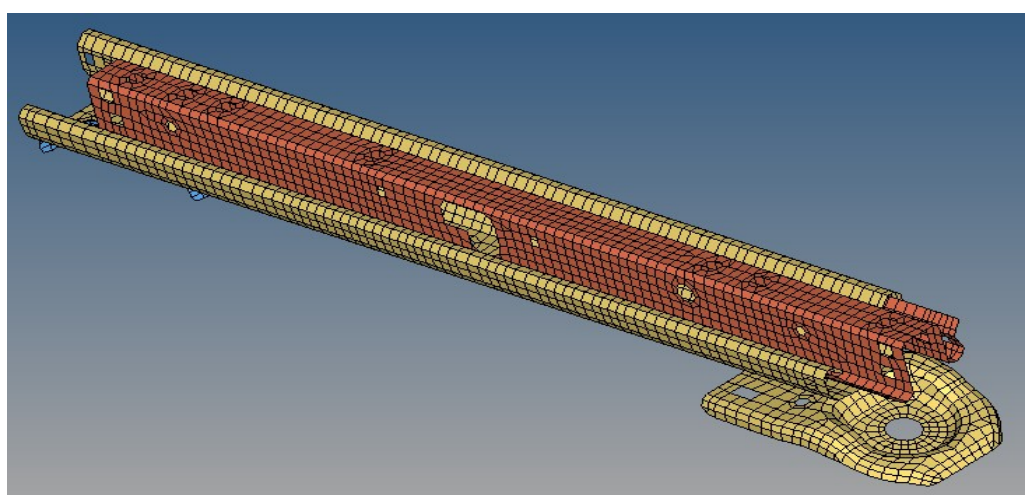

Fig: 2 Finite Element modeling of seat track. 


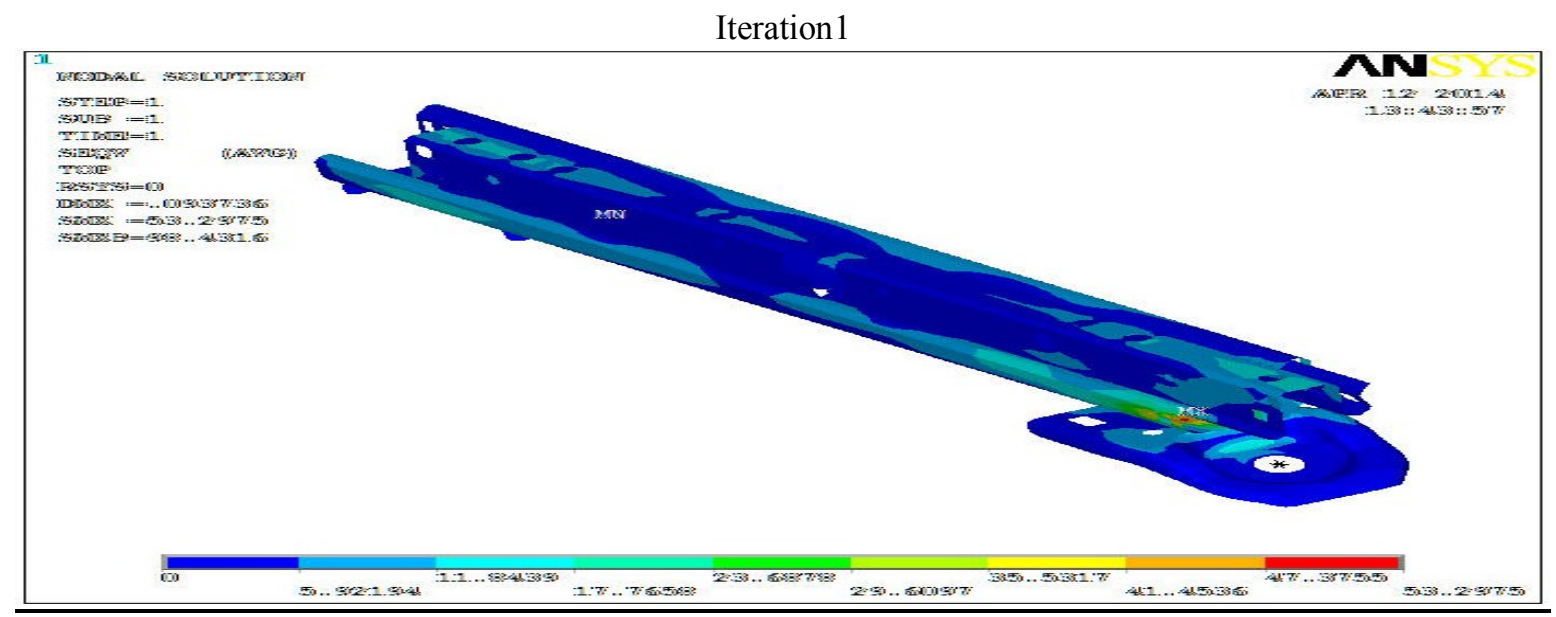

Fig: 3 Von Mises Stress Plot.

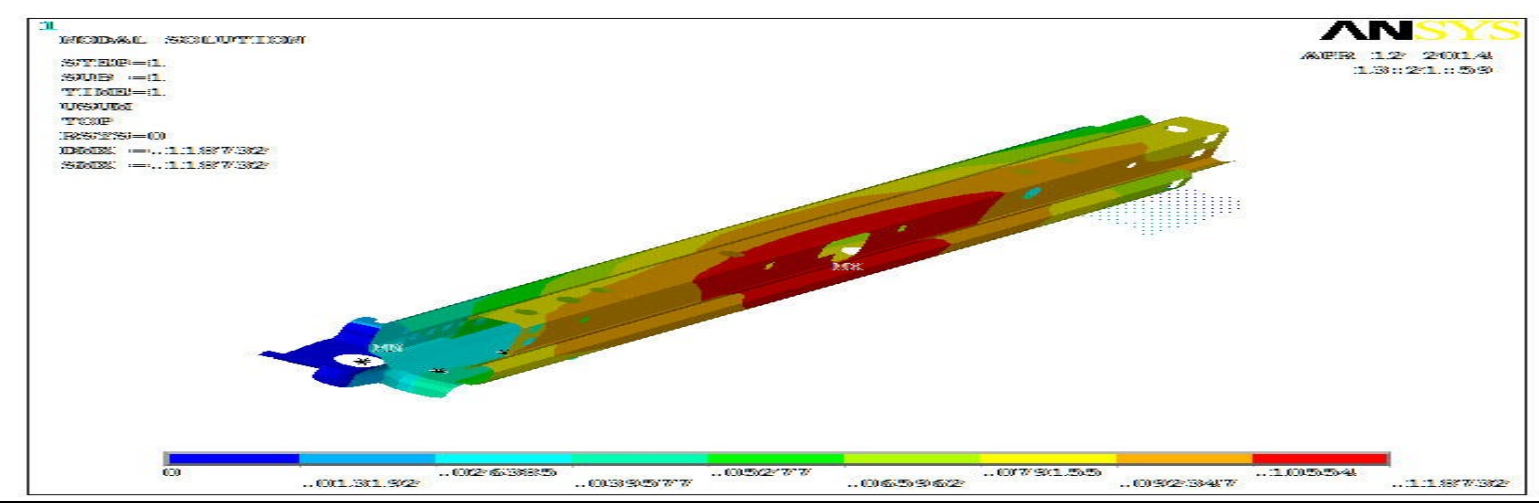

Fig:4 Deformation Plot.

Iteration 3.

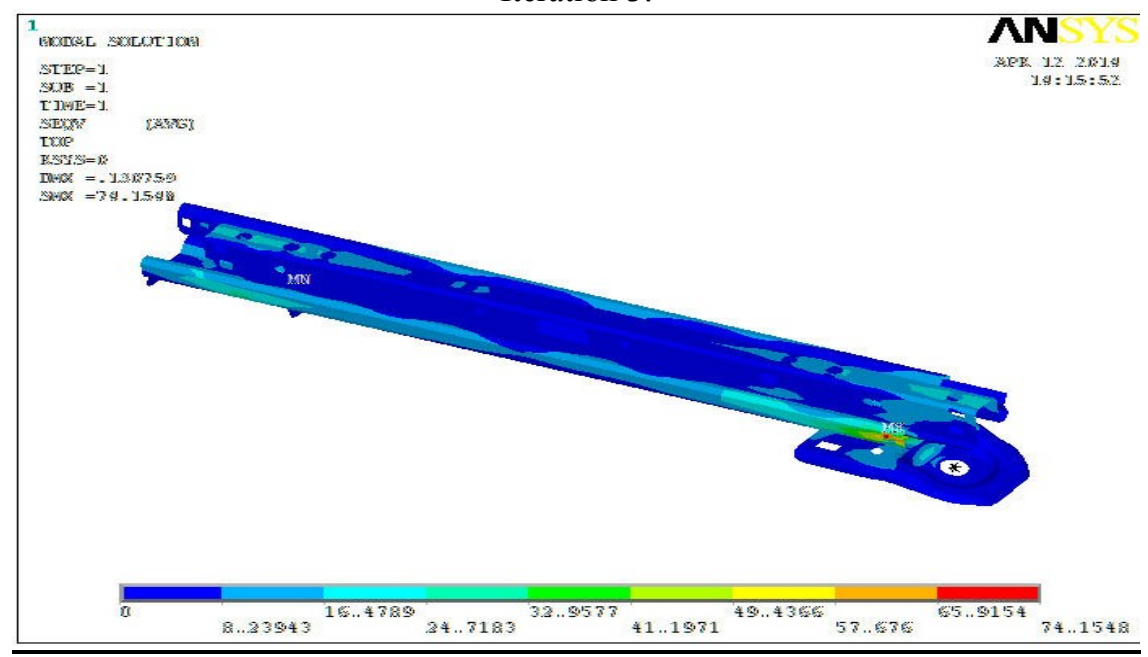

Fig: 3 Von Mises Stress Plot 


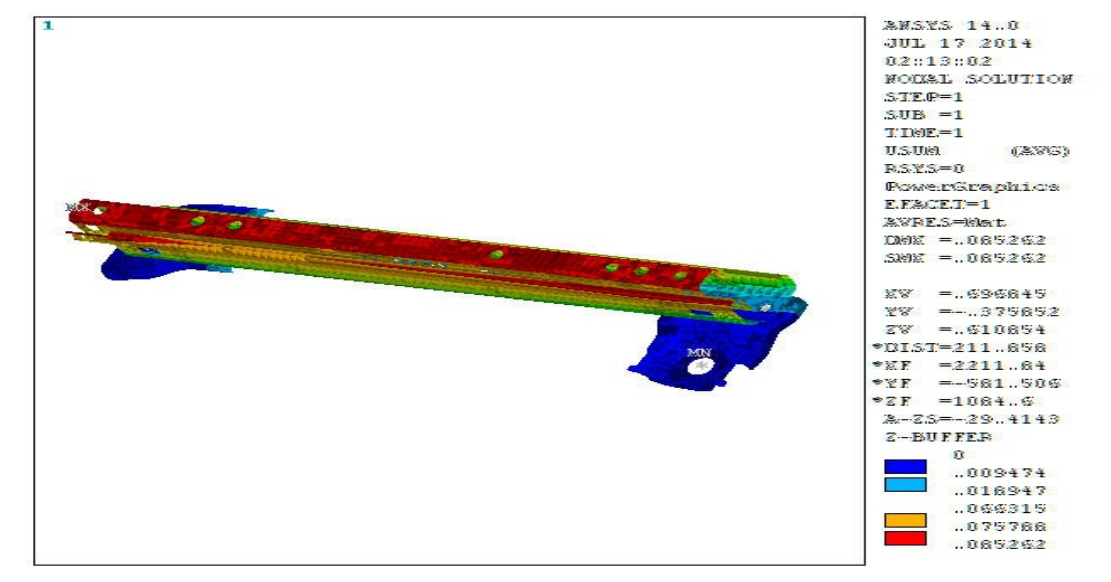

Fig:4 Deformation Plot.

Table 2:

\section{Conclusion}

\begin{tabular}{|c|c|c|c|c|c|}
\hline $\begin{array}{l}\text { Upper track } \\
\text { thickness }\end{array}$ & $\begin{array}{r}\text { Load acting } \\
\text { on each track }\end{array}$ & $\begin{array}{l}\text { Von misses stress } \\
\text { Mpa }\end{array}$ & $\begin{array}{l}\text { Yield stress } \\
\text { Mpa }\end{array}$ & $\begin{array}{l}\begin{array}{l}\text { Factor of } \\
\text { safety }\end{array} \\
\end{array}$ & $\begin{array}{l}\text { Weight } \\
\mathrm{Kg}\end{array}$ \\
\hline $1.5 \mathrm{~mm}$ & $70 \mathrm{KG}$ & 53.59 & \multirow{5}{*}{$250 \mathrm{Mpa}$} & 4.71 & 1.381 \\
\hline $1.25 \mathrm{~mm}$ & $70 \mathrm{KG}$ & 66.79 & & 3.74 & 1.52 \\
\hline $1.15 \mathrm{~mm}$ & $70 \mathrm{KG}$ & 74.158 & & 3.2 & 1.114 \\
\hline $1.15 \mathrm{~mm}$ & $90 \mathrm{KG}$ & 98.87 & & 2.52 & 1.114 \\
\hline \multirow[t]{2}{*}{$1.15 \mathrm{~mm}$} & $80 \mathrm{KG}$ & 85.69 & & 2.91 & 1.114 \\
\hline & & & \multicolumn{2}{|c|}{ Reduction in Weight } & 0.267 \\
\hline
\end{tabular}

From the above static analysis of seat track we have seen that, the obtained FOS for seat track of thickness $1.15 \mathrm{~mm}$ bearing $70 \mathrm{~kg}$ of load is within limit, i.e. 3-3.5; and the optimized seat rails assembly has

$>$ Reduced thickness

$>$ Less mass and

$>$ Low cost.

\section{Future Scope of the Project}

In this project the seat track is analyzed using carbon steel material, i.e. ASTM A311/A 311M. In order to reduce the cost, weight and to increase the efficiency of an automobile as it is the main aim of an automotive industry; composite material is used so that there is an overall cost reduction and weight of the seat track with an increased strength and safety feature.

\section{References}

[1]. Analysis and Optimization of Seat Rail assembly by Akbar Basha S, Surendra P

[2]. Anti-submarine performance of an automotive seating system- A DoE study by Pavan Gupta. Vijay Ananda R Dhavanti Sindhe Jayant D Joshi Sreenivaasa Rao Nunna, K S Ramanath.

[3]. D. M. Severy, H. M Brink and J. D. Baird, "Collision Performance LM Safety Car", SAE No 670458, SAE Mid Year Meeting Chicago Illinois, (1967).

[4]. F W Babbs and B C Hilton. "The packaging of car Occupants - A British Approach to seat design”, Chapter 32, Seventh STAPP car crash conference, (1967).

[5]. Prediction of failure on high strength steel in seat mechanisms simulation by M. Chauffray, G. Delattre, L. Guerin.

[6]. Challenges involved with developing seat slide assemblies using advanced high strength steels Tim Macnaughtan P.Eng.Dura Automotive Systems.

[7]. A. W. Siegel, A. M. Nahum and D. E. Runge, "Bus Collision Causation and Injury Patterns", SAE No 710860, Proceedings of Fifteenth STAPP Car crash Conference Society of Automotive Engineers Inc., (1971).

[8]. Toshiki Nonka, Koichi Goto, Hirokazu Taniguchi and Kazumasa Yamazaki "Development of Ultra-High Strength Cold-Rolled Steel Sheets for Automotive Use", Nippon Steel Technical Report No. 88 (2003).

[9]. Seat mechanism for vehicle by Kazutaka Susaki, Hidehiko Fujioka, Masato Horie.

[10]. Seat structure for vehicle by Morris Markin, Kalamazoo, Mich. 